\section{Effect of Irrigation Scheduling on Gerbera Flower Yield and Quality}

\author{
Ioannis Tsirogiannis ${ }^{1}$ \\ Department of Floriculture and Landscape Architecture, Faculty of \\ Agricultural Technology, Technological Educational Institute of Epirus, \\ Arta, Greece
}

\author{
Nikolaos Katsoulas ${ }^{1}$ and Constantinos Kittas ${ }^{2,3}$ \\ Department of Agriculture Crop Production and Rural Environment, School \\ of Agricultural Sciences, University of Thessaly, Fytokou Street N. Ionia, \\ Volos, Magnesia 38446, Greece
}

Additional index words. soilless cultivation, leaf area index, reflectance index, crop transpiration

\begin{abstract}
Better understanding of the effects of irrigation frequency and dose on flower production of gerbera plants (Gerbera jamesonii) can lead to optimal water management and crop yield. Measurements of greenhouse microclimate and production and quality characteristics of a gerbera crop were carried out under two irrigation frequency regimens in soilless cultivation in a greenhouse located in Arta, Greece. Irrigation scheduling was based on solar radiation and performed whenever accumulated solar radiation energy outside the greenhouse reached $1650 \mathrm{~kJ} \cdot \mathrm{m}^{-2}$ [high irrigation frequency (HIF)] or $3300 \mathrm{~kJ} \cdot \mathrm{m}^{-2}$ [low irrigation frequency (LIF)]. The amount of water applied was $0.125 \mathrm{~mm}$ and $0.250 \mathrm{~mm}$ for HIF and LIF, respectively. Stem fresh weight, length and thickness, and number of harvested gerbera flowers were measured along with crop evapotranspiration, crop leaf area, and greenhouse microclimate variables. Measurements started 8 months after transplanting and lasted 90 days (May to July). Leaf area, fresh weight, harvested cut flowers, and the main quality characteristics of gerbera flowers (stem length and flower diameter) were unaffected by the irrigation frequency. In the framework of the experiment, simple formulas for calculation of leaf area index were developed. Finally, a first approach study of an alternative remote sensing irrigation control method using a reflectance index was made and the results are presented.
\end{abstract}

Optimal irrigation scheduling could lead to higher water use efficiency, an objective of very high importance nowadays. Adequate supply of water and nutrients results in higher water and nutrient use efficiency, better production control, and avoidance of stress situations (Raviv and Blom, 2001). Irrigation control involves determination of both timing and quantity of each watering event. Methods for irrigation scheduling are usually based on calculation of crop evapotranspiration commonly performed by means of an energy balance method (Allen et al., 1998; Donatelli et al., 2006) and estimation of the couple frequency-dose.

Automatic control of irrigation events in the greenhouse is usually based on solar radiation (Katsoulas et al., 2006; Stanhill and Scholte, 1974). A solar energy integrator transmits a switching-on signal to the water supply system after a preset level of energy is reached. An irrigation control system based on the main factor affecting crop evapotrans-

\footnotetext{
Received for publication 22 July 2009. Accepted for publication 13 Dec. 2009.

We thank Dr. Ch. Nakas, Lecturer of the University of Thessaly, for his help in applying time series analysis to the data.

${ }^{1}$ Lecturer.

${ }^{2}$ Professor

${ }^{3}$ To whom reprint requests should be addressed; e-mail ckittas@uth.gr.
}

piration in the greenhouse can supply nutrient solution to plants without unnecessary water and nutrient losses (Roh and Lee, 1996). However, this method implies the knowledge of several crop parameters, most of them varied in function to crop phenological stage. Gerbera plants, because of frequent removal of old or damaged leaves, exhibit a fluctuation of leaf area, something that implies extra difficulties when attempting to formulate any model for scheduling irrigation.

An alternative, optimal irrigation control approach would also include real-time plant water status monitoring and crop water stress indices. A variety of indices have been used to express crop water status and control irrigation events. Leaf water potential and stomatal conductance provide evidence of water stress, but they cannot be measured online and accordingly cannot be incorporated in automated systems (Katerji et al., 1988). Cure et al. (1989) found that crop water stress induced changes in the daily patterns of canopy temperature and canopy radiation reflectance. Similar results have been also found by other authors (Ceccato et al., 2001; Moran et al., 1989, 1994; Peñuelas et al., 1992; Riggs and Running, 1991) relating crop water stress to crop radiation reflection. Canopy radiation reflectance is mainly affected by crop leaf reflectance behavior, but also by the nonuniformity of incident solar radiation, by the plant structure, the leaf area index, possible shadows, and background reflectance (Thenot et al., 2002). In case that crop is under stress, reflectance properties of individual leaves are affected with the most obvious changes occurring in the visible spectral region rather than in the infrared because of the sensitivity of chlorophyll to physiological disturbances (Knipling, 1970). According to Cure et al. (1989) and Moran et al. (1989), characteristically, the primary sign for stress conditions detection by reflectance sensors is not a change of the reflectance characteristics of individual leaves, but a reduction of the total leaf area exposed to sensors. However, for short time periods, reduction of leaf area exposed may be observed as a result of leaves' orientation changes. It has been reported that the yellow-red visible region $(\approx 560 \mathrm{~nm}$ to $710 \mathrm{~nm}$ ) reflectance tends to increase with increasing water stress, whereas the near infrared region (above $760 \mathrm{~nm}$ ) reflectance tends to decrease with increasing water stress (Nantt, 2008). Peñuelas et al. (1994) found that at sunflower cultivation, the physiological reflectance index (PRI $=\mathrm{R}_{550}-\mathrm{R}_{530} / \mathrm{R}_{550}+$ $\mathrm{R}_{530}$ ) decreases and, on the contrary, the water band index (WBI) $\left(\mathrm{R}_{970} / \mathrm{R}_{902}\right)$ increases with water stress, whereas other authors (Thenot et al., 2002) agreed that PRI could be used as a water stress index. Ceccato et al. (2001) concluded that the simple ratio $\left(\mathrm{R}_{1600} / \mathrm{R}_{820}\right)$ could be used as a first approximation to retrieve vegetation water content at leaf level.

As far as the irrigation dose is concerned, this depends mainly on crop substrate characteristics such as easily available water (EAW). EAW is relatively low in pumice (Gizas and Savvas, 2007) and, therefore, more frequent irrigation with low water doses is recommended when this substrate is used for soilless cultivation. Maloupa et al. (1996) found that for mild climate conditions, a low irrigation frequency (approximately eight irrigation events per day) satisfies the water requirements of gerbera grown in various substrates. Additionally, setting up an irrigation schedule is also linked to container size (Gizas and Savvas, 2007; Manios et al., 1995).

The main objective of the present study was to evaluate the effects of two irrigation frequencies on gerbera flower yield (flower number and quality) grown in pots filled with pumice in an open hydroponic system. A secondary objective of this work was to carry out a first approach study of irrigation control based on remote sensing methods.

\section{Materials and Methods}

Greenhouse facilities and plant material. The experiment was carried out from May to July 2008 in an east-west-oriented, twinspan, glass-covered greenhouse located at the Technological Education Institute of Epirus, near Arta (long. 39 $9^{\circ} \mathrm{N}$, lat. 20 $0^{\circ} 56^{\prime} \mathrm{E}$, altitude $5 \mathrm{~m}$ ) on the coastal area of western Greece. The geometrical characteristics of the greenhouse were as follows (Fig. 1): eaves height $=3.15 \mathrm{~m}$, ridge height $=4.40$ $\mathrm{m}$, span width $=6.50 \mathrm{~m}$, total length $=46 \mathrm{~m}$, ground area $=600 \mathrm{~m}^{2}$, volume $=2270 \mathrm{~m}^{3}$. 


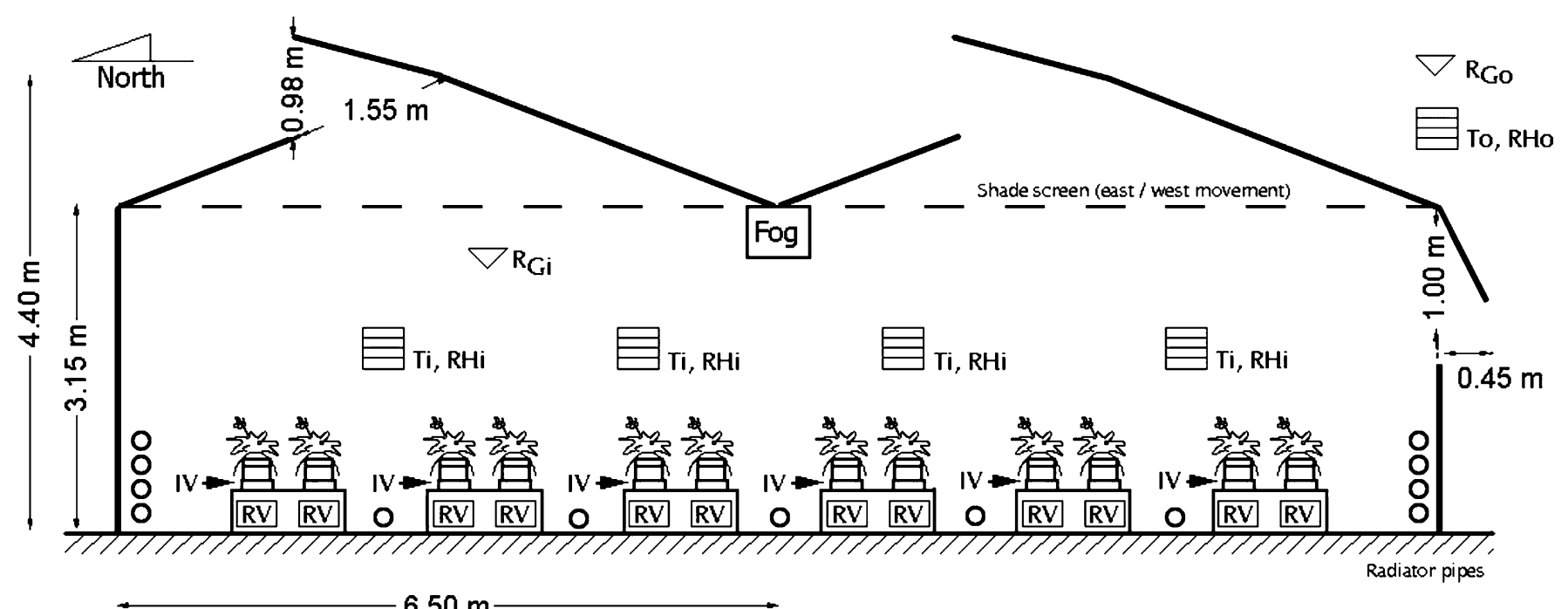

$6.50 \mathrm{~m}$

$13.00 \mathrm{~m}$

Fig. 1. Experimental greenhouse and meteorological instruments: $\mathrm{T}, \mathrm{RH}=$ air temperature and relative humidity sensor (subscripts: $\mathrm{o}=$ outside, $\mathrm{i}=\mathrm{inside}$ ); $\mathrm{R}_{\mathrm{G}}=$ pyranometer (subscripts: $\mathrm{o}=$ outside, $\mathrm{i}=$ inside); $\mathrm{RV}=$ drained nutrient solution; $\mathrm{IV}=$ volume of irrigation water supplied to each bench.

Ventilation was performed by means of roof and side openings. The greenhouse was equipped with a single continuous roof vent per span located at the north side and a side vent at the south wall. The roof vents were $45.90 \mathrm{~m}$ long and $1.55 \mathrm{~m}$ wide with a maximum opening area per vent of $43 \mathrm{~m}^{2}$, whereas the side vent was $45.90 \mathrm{~m}$ long and $1.00 \mathrm{~m}$ wide with a maximum opening area equal to $23 \mathrm{~m}^{2}$. The vents were opened whenever air temperature was higher than $22^{\circ} \mathrm{C}$ (Katsoulas et al., 2007). Furthermore, the greenhouse was equipped with a movable, aluminized thermal screen located horizontally at the eaves level, which was used for the reduction of solar radiation reaching the plant canopy.

The greenhouse floor was completely covered by concrete. The experiment was conducted at the central part of the greenhouse $\left(160 \mathrm{~m}^{2}\right)$ on 12 benches (height, length, width: $0.86 \mathrm{~m}, 4.96 \mathrm{~m}$, and $1.10 \mathrm{~m}$, respectively). Each bench accommodated two channels $(4.96 \mathrm{~m} \times 0.25 \mathrm{~m}, 0.40 \mathrm{~m}$ apart $)$ on its upper surface, which were independently supplied with nutrient solution by a drip irrigation system. All channels were covered by a double-sided (black downward, white upward) plastic film to prevent nutrient solution evaporation. Eighteen pots (with one plant each) were placed in each channel and thus the total crop density was 2.7 plants $/ \mathrm{m}^{2}$. It has to be noted that under commercial gerbera cultivation, plant density is approximately eight to 10 plants $/ \mathrm{m}^{2}$ (Rogers and Tjia, 1990).

Gerbera plants (Gerbera jamesonii cv. Balance $\left.{ }^{\circledR}\right)$, which had been raised in Jiffy plugs $(6 \mathrm{~cm})$, were transplanted on 21 Sept. 2007 in 4 -L pots (one plant per pot). The pots were filled with Nisyros pumice, not washed before use, with particle size ranging from $0 \mathrm{~mm}$ to $5 \mathrm{~mm}$. The characteristics of the substrate were: bulk density $=720 \mathrm{~kg} \cdot \mathrm{m}^{-3}$, porosity $=72 \%$ (Manios et al., 1995), and actual water content at container capacity $=$ 37.6\% (Gizas and Savvas, 2007).
Irrigation: system, schedule, and control. Water and fertilizers were supplied through a drip system. Two pressure-compensating emitters of $2.2 \mathrm{~L} \cdot \mathrm{h}^{-1}$ each were stapled on each pot. The system was automatically controlled by a fertigation computer (Autonet Ltd., Athens, Greece). The target $\mathrm{pH}$ and electrical conductivity values were 5.6 and $1.72 \mathrm{dS} \cdot \mathrm{m}^{-1}$, respectively.

As can be estimated using the water retention curve of pumice 0 to $5 \mathrm{~mm}$ (Gizas and Savvas, 2007), the water volume to be supplied per irrigation event to a 4-L pot filed with pumice should not exceed $100 \mathrm{~mL}$ to maintain the moisture status within the range of easily available water (10 to $50 \mathrm{~cm})$. Two different irrigation frequencies were applied in a randomized block design with six blocks. The amount of water applied (IR) per irrigation event to each treatment was $0.125 \mathrm{~kg} \cdot \mathrm{m}^{-2}$ $(50 \mathrm{~mL} /$ pot $)$ and $0.250 \mathrm{~kg} \cdot \mathrm{m}^{-2}(100 \mathrm{~mL} /$ pot $)$ for high irrigation frequency (HIF) and low irrigation frequency (LIF), respectively. Accordingly, because the HIF treatment was irrigated twice the times the LIF treatment was, the total water applied was equal in both cases.

The amount of water applied IR can be calculated using the relation (Katsoulas et al., 2006):

$$
\mathrm{IR}=\mathrm{T}_{\mathrm{r}} /(1-\mathrm{dr})
$$

where $d r$ is the drainage rate and $T_{r}$ is the crop transpiration in $\mathrm{kg} \cdot \mathrm{m}^{-2}$, which can be estimated using the simple relation:

$$
\mathrm{T}_{\mathrm{r}}=\zeta \mathrm{R}_{\mathrm{Go}}
$$

where $\mathrm{R}_{\mathrm{Go}}$ is the time integral of solar radiation outside the greenhouse in $\mathrm{kJ} \cdot \mathrm{m}^{-2}$ and $\zeta$ a coefficient given by:

$$
\zeta=\mathrm{K}_{\mathrm{c}} \tau \alpha / \lambda
$$

where $K_{c}$ is the crop coefficient; $\tau$ is the greenhouse cover transmission to solar radiation; $\alpha$ is the evaporation coefficient and represents the part of the energy of incoming solar radiation that is transformed to latent heat through transpiration; and $\lambda$ is the latent heat of vaporization of water in $\mathrm{kJ} \cdot \mathrm{kg}^{-1}$.

The drainage rate was maintained near $40 \%$ to maintain optimal conditions of water supply to the plants (Akat et al., 2009; Maloupa et al., 1993). The greenhouse cover transmission to solar radiation, $\tau$, was calculated as the mean ratio of incoming to outside solar radiation. During the period of measurements, a thermal screen was used for greenhouse shading, and the average greenhouse cover transmission was 0.41 . The mean value of the crop coefficient, $\mathrm{K}_{\mathrm{c}}$, was taken equal to 0.45 (Maloupa et al., 1993, 1996; Papadopoulos et al., 1995) (slight alterations of $\mathrm{K}_{\mathrm{c}}$ were made based on crop leaf area index changes and on the percentage of drainage solution), and the evaporation coefficient, $a$, was taken as equal to 0.6 , as is usually observed for greenhouse cultivations (Baille, 1999).

The frequency of irrigation was based on solar radiation measured by a pyranometer located outside the greenhouse (to avoid transient sensor shading problems resulting from structural elements). Using Eqs. (1), (2), and (3), the solar radiation integral outside the greenhouse $\mathrm{R}_{\mathrm{G}, \mathrm{o}}$ needed for an irrigation event to start was calculated and the values found were $1650 \mathrm{~kJ} \cdot \mathrm{m}^{-2}$ for HIF and 3300 $\mathrm{kJ} \cdot \mathrm{m}^{-2}$ for LIF.

Measurements. The following data were recorded inside the greenhouse (Fig. 1):

Air temperature $\left(\mathrm{T}_{\mathrm{i}}\right.$, in $\left.{ }^{\circ} \mathrm{C}\right)$ and relative humidity ( $\mathrm{RH}$, in \%) by means of four temperature and humidity sensors homogeneously distributed inside the greenhouse compartment and one pair of sensors outside the greenhouse (Model HD9008TR; DeltaOhm, Padua, Italy). Using these data, the mean value of greenhouse air temperature and $\mathrm{RH}$ and water vapor pressure were calculated (Allen et al., 1998); 
Outside and incoming solar radiation $\left(\mathrm{R}_{\mathrm{G}, \mathrm{o}}\right.$ and $\mathrm{R}_{\mathrm{G}, \mathrm{i}}$ in $\mathrm{W} \cdot \mathrm{m}^{-2}$ ) by means of solar pyranometers (Model SKS 1110; Skye Instruments, Powys, U.K.) located at $\approx 4.5 \mathrm{~m}$ and $2.5 \mathrm{~m}$ above the ground, respectively; and

Volume of irrigation water (IV) supplied to each bench by means of digital flow meters (Model DN 25; Actaris, BoulogneBillancourt, France).

All the mentioned measurements were collected on a data logger system (DL2e Logger; Delta-T Devices Ltd., Cambridge, U.K.). Measurements took place every $30 \mathrm{~s}$, and the 10-min average values were recorded.

Furthermore, all drainage water was collected in tanks at the edge of each bench and the volume of drainage water (RV) of each bench was measured manually every week. The leaf area index $\left(\mathrm{I}_{\mathrm{LA}}: \mathrm{m}^{2}\right.$ leaf $/ \mathrm{m}^{2}$ ground $)$ of the crop was estimated by destructive measurements of the leaf area of sample plants by means of a scanner (GT 9500; Epson, Nagano, Japan). The plants removed for destructive measurements were replaced by buck-up plants of the same size. Leaf area measurements were carried out three times during the experimental period, namely on 15 May, 15 June, and 15 July; and the leaf area, the length, and width of the individual leaves of four plants per treatment and date were measured. To calculate the leaf area, the Monte-Carlo arithmetic integration method (Robert and Casella, 2005) was applied to leaf scanned images.

Inflorescences were considered ready for harvesting when at least two full circles of ripened male flowers were seen. Harvest was made during the morning once per week. Flower yield measurements included measurements of the number, fresh weight (by means of a weighting balance, Model 60000 G SCS; Precisa Gravimetrics AG, Dietikon, Switzerland), stem length and flower diameter of the harvested gerbera flowers (by means of a measure tape), and stem thickness (by means of an electronic caliper).

Finally, during $1 \mathrm{~d}$ of the experimental period (16 June), leaf stomatal resistance $\left(r_{c}\right)$ was measured by a porometer (LI-1600M; LICOR Inc., Lincoln, NE) and the radiation reflected by the canopy $\left(R_{R}\right)$ was measured using a portable multispectral radiometer (Model MSR87; CropScan Inc., Rochester, $\mathrm{MN}$ ) in eight narrow bands centered at the following wavelengths (in $\mathrm{nm}$ ): 460, 510, 560, $610,660,710,760$, and 810 . The radiometer was located $1.5 \mathrm{~m}$ above the canopy level (sampled canopy area of $0.44 \mathrm{~m}^{2}$, manufacturer data), whereas during the period of radiation reflection measurements, the thermal screen was in the collect position. At the same time, $r_{c}$ measurements were carried out. The radiation data measured were used to calculate a reflectance index (RI) using a formula similar to the PRI formula:

$$
\mathrm{RI}=\mathrm{R}_{560}-\mathrm{R}_{510} / \mathrm{R}_{560}+\mathrm{R}_{510}
$$

where $R_{510}$ and $R_{560}$ are the radiation reflectance at $510 \mathrm{~nm}$ and $560 \mathrm{~nm}$, respectively. It has to be noted that PRI uses the radiation reflected at 530 and $550 \mathrm{~nm}$; however, the instrument used in this study to measure radiation reflectance could not measure at these narrow bands and thus, the values measured at 510 and 560, respectively, were used.

Selected data were analyzed and comparison of means was performed by applying the Student $t$ test at a confidence level of $95 \%$ using the PlotIT software package (Scientific Programming Enterprises, Haslett, MI).

\section{Results and Discussion}

Greenhouse microclimate. The mean values of the greenhouse and the outside climate variables (average over the period 0800 to 19:00 HR local time) during the period of measurements are presented in Table 1.

Leaf area. A good correlation was obtained between leaf area $\left(\mathrm{S}, \mathrm{cm}^{2}\right)$ and the product $\mathrm{L} \times \mathrm{W}$ of length $(\mathrm{L}, \mathrm{cm})$ and width $(\mathrm{W}, \mathrm{cm})$ of each leaf. The relationship obtained by linear regression was:

$$
\mathrm{S}=0.57 \mathrm{~L} \cdot \mathrm{W}
$$

for both irrigation treatments with a value for the coefficient of determination $\left(R^{2}\right)$ of 0.83 . Simple linear formulas for calculation of gerbera leaf area have already been proposed (for example, $\mathrm{S}=6.166+0.308 \cdot \mathrm{L} \cdot \mathrm{W}$; Maloupa et al., 1996) but did not fit our data, probably because a different gerbera cultivar was used in the present study.

A simpler and more convenient for practical purposes, expression for the calculation of leaf area index $\left(\mathrm{I}_{\mathrm{LA}}\right)$ involving the number of leaves per plant (n) and the plant density (p) was also found:

$$
\mathrm{I}_{\mathrm{LA}}=0.0083 \mathrm{n} \mathrm{p}
$$

for both irrigation treatments with an $R^{2}$ value of 0.84 .

The overall average number of leaves per plant for both treatments was 16.78 (with a SD of \pm 5.61 leaves). The mean value of $\mathrm{I}_{\mathrm{LA}}$ was $0.45( \pm 0.1)$ and $0.41( \pm 0.1)$ for the HIF and LIF treatments, respectively $\left(10 \%\right.$ higher $\mathrm{I}_{\mathrm{LA}}$ values under HIF than under LIF). However, these values were not significantly different between the two treatments. Fluctuations of $\mathrm{I}_{\mathrm{LA}}$ values during the period of measurements (Table 2) are the result of continuous removal of old or damaged leaves and emergence of new leaves (Rogers and Tjia, 1990). Similar results have been also found by Katsoulas et al. (2006) who studied the effect of two irrigation frequencies on leaf area of a rose crop grown on rockwool slabs in a closed hydroponic system.
Cut flower yield and quality. As can be seen in Figure 2, a fluctuation on the number of harvested flowers was observed during the period of measurements with the number of harvested flowers being most of the time higher for the plants irrigated with LIF. However, statistical analysis of the data revealed that there were no significant differences between the two treatments. The decrease of harvested flowers during the end of June to the beginning of July was probably the result of high temperature levels observed during this period (above $38{ }^{\circ} \mathrm{C}$ ), which may induced diminution in growth and blooming [optimal temperature range for gerbera is between 17 and $27^{\circ} \mathrm{C}$ (Rogers and Tjia, 1990)]. The total number of harvested flowers $/ \mathrm{m}^{2}$ after a cultivation period of 3 months was 35.20 for the LIF and 30.12 for the HIF treatments with no statistical differences between the values observed for the two treatments. Katsoulas et al. (2006) found that for a rose crop and for the irrigation frequencies tested under their study, the higher the irrigation frequency, the higher the yield, because the total number of cut flowers measured was $\approx 28 \%$ higher under HIF than under LIF.

With respect to fresh weight per flower, both treatments follow almost the same trend during the period of measurements (data not shown) and the statistical analysis showed that there were no significant differences in terms of fresh weight per flower between the two treatments. The mean value of flower fresh weight (in grams per flower) was 22.9 $( \pm 5.1)$ for HIF and $24.4( \pm 6.2)$ for LIF. However, the evolution of cumulative harvested flower fresh weight per greenhouse ground area (Fig. 3) followed a similar trend in both treatments with the values for LIF being always higher than those for the HIF treatment. The cumulative values observed after a harvesting period of 3 months were $933.94 \mathrm{~g} \cdot \mathrm{m}^{-2}$ and $764.27 \mathrm{~g} \cdot \mathrm{m}^{-2}$ for the LIF and HIF, respectively. Accordingly, a higher cumulated fresh weight of $\approx 22 \%$ was observed for the LIF plants.

Stem length and flower diameter are the primary indicators for the market value of cut-flower gerbera yield. The expected quality characteristics of $\mathrm{cv}$. Balance used in the present study were stem length of $60 \mathrm{~cm}$ and flower diameter between $10 \mathrm{~cm}$ and $12 \mathrm{~cm}$ (Anonymous, 2007). Figure 4 shows the evolution of mean cut flowers' stem length during the period of measurements. Mean stem length value was $59 \mathrm{~cm}( \pm 7 \mathrm{~cm})$ for both treatments with no significant differences between the two treatments. Under LIF, gerbera plants produced slightly bigger

Table 1. Average values of greenhouse and outside climate parameters during the period of measurements. ${ }^{\mathrm{z}}$

\begin{tabular}{lcccccc}
\hline Period & $\mathrm{T}_{\mathrm{i}}\left({ }^{\circ} \mathrm{C}\right)$ & $\mathrm{RH}_{\mathrm{i}}(\%)$ & $\mathrm{D}_{\mathrm{i}}(\mathrm{kPa})$ & $\mathrm{R}_{\mathrm{Gi}}\left(\mathrm{W} \cdot \mathrm{m}^{-2}\right)$ & $\mathrm{T}_{\mathrm{o}}\left({ }^{\circ} \mathrm{C}\right)$ & $\mathrm{R}_{\mathrm{Go}}\left(\mathrm{W} \cdot \mathrm{m}^{-2}\right)$ \\
\hline May & $31.6( \pm 6.3)$ & $53.2( \pm 12.4)$ & $2.6( \pm 0.6)$ & $272( \pm 175)$ & $24.8( \pm 4.1)$ & $639( \pm 299)$ \\
June & $37.4( \pm 7.1)$ & $49.9( \pm 13.2)$ & $3.2( \pm 0.5)$ & $274( \pm 170)$ & $29.9( \pm 4.6)$ & $669( \pm 294)$ \\
July & $38.8( \pm 6.4)$ & $50.6( \pm 12.0)$ & $2.8( \pm 0.6)$ & $288( \pm 177)$ & $31.6( \pm 3.6)$ & $673( \pm 287)$ \\
\hline
\end{tabular}

${ }^{\text {zThe }} \mathrm{SD}$ of the values is given in parentheses.

$\mathrm{T}_{\mathrm{i}}=$ greenhouse air temperature; $\mathrm{RH}_{\mathrm{i}}=$ greenhouse air relative humidity; $\mathrm{D}_{\mathrm{i}}=$ greenhouse air vapor pressure deficit; $\mathrm{R}_{\mathrm{Gi}}=$ internal solar radiation; $\mathrm{T}_{\mathrm{o}}=$ outside air temperature; $\mathrm{R}_{\mathrm{Go}}=$ outside solar radiation. 
flowers than under HIF (Fig. 5), but no significant differences were found in flower diameter between the two treatments. Mean flower diameter was $11.5 \mathrm{~cm}( \pm 1)$ for both

According to Rogers and Tjia (1990), gerbera plants require a constant supply of water, but the surface of the substrate should be dry between irrigation events. Although it is possible that the constant wet substrate surface induced by HIF and the possibility

Table 2. Leaf area index $\left(\mathrm{I}_{\mathrm{LA}}\right)$ of the crop measured under high (HIF) and low (LIF) irrigation frequency. ${ }^{z}$

\begin{tabular}{lcc}
\hline Date & HIF & LIF \\
\hline 15 May 2008 & $0.41( \pm 0.10)$ & $0.37( \pm 0.08)$ \\
15 June 2008 & $0.49( \pm 0.09)$ & $0.45( \pm 0.11)$ \\
15 July 2008 & $0.44( \pm 0.12)$ & $0.42( \pm 0.11)$ \\
Mean value & $0.45( \pm 0.10)$ & $0.41( \pm 0.10)$ \\
\hline
\end{tabular}

${ }^{2} \mathrm{SD}$ of the values is given in parentheses. treatments.

that pumice's particle size ( 0 to $5 \mathrm{~mm}$ ) combined with HIF did not provide good aeration conditions to the plants negatively (no statistically significant) affected gerbera yield. The application of a frequent irrigation schedule is possible to create excessive moisture conditions in the root zone that might reduce oxygen availability (Schroder and Lieth, 2002; Sonneveld, 1989).

Crop transpiration and total water consumption. Crop transpiration rate $(\mathrm{Tr}$, in $\mathrm{kg} /$ plant/day) was estimated using weekly measurements of the water volume supplied to the crop (IV) and the water collected by the drainage system (RV) by means of a simplified water balance model (Maloupa et al., 1996; Papadopoulos et al., 1995):

$$
\operatorname{Tr}=(\mathrm{IV}-\mathrm{RV} \pm \mathrm{DSM}) / \mathrm{n}
$$

where $\Delta \mathrm{SM}$ is the difference in substrate moisture between measurements and $\mathrm{n}$ is

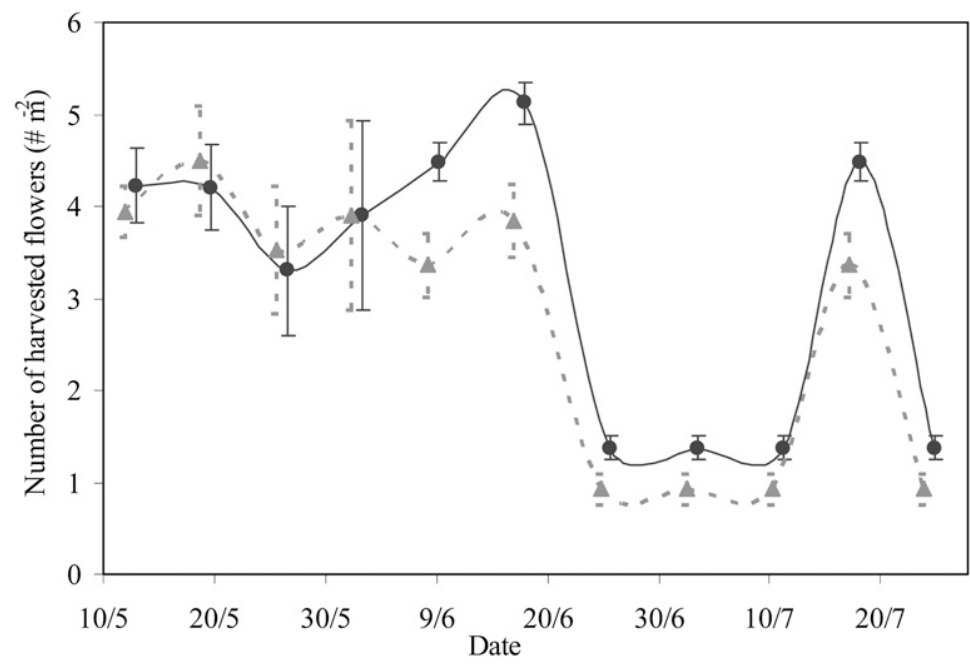

Fig. 2. Evolution of number of harvested stems $/ \mathrm{m}^{2}$ of greenhouse ground area; circles: low irrigation frequency; triangles: high irrigation frequency (vertical bars depict \pm SES of means of six measurements).

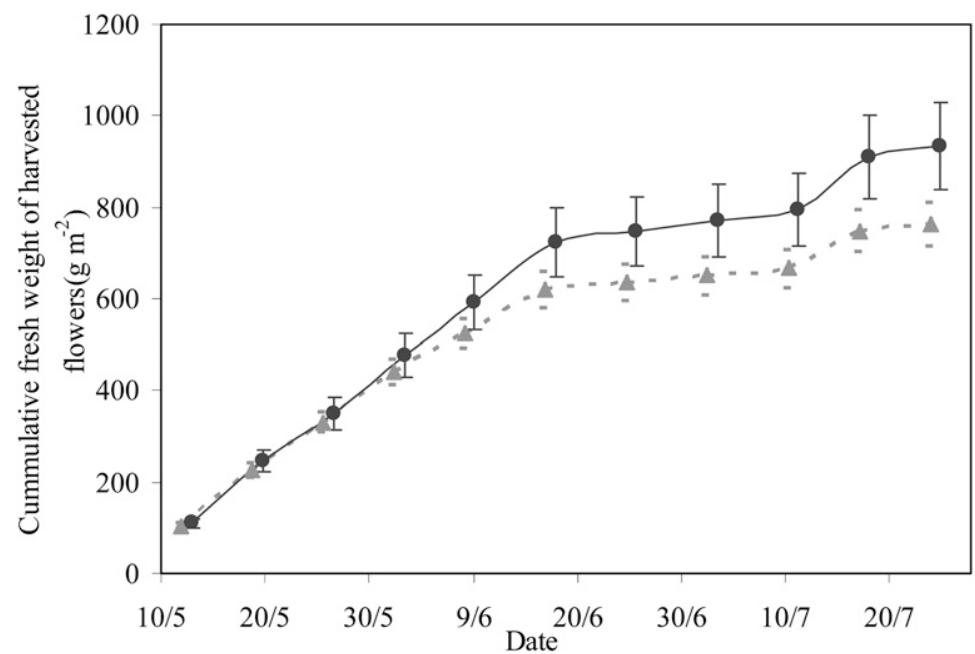

Fig. 3. Development of cumulative harvested stem fresh weight $/ \mathrm{m}^{2}$ of greenhouse ground area; circles: low irrigation frequency; triangles: high irrigation frequency (vertical bars depict \pm sEs of means of six measurements). the corresponding number of days referred to the period of IV and RV measurements. As a result of the low frequency (once per week) of measurements, the difference in substrate moisture can be neglected, because its magnitude is very small compared with the other parameters of Eq. [7] (Allen et al., 1998; Papadopoulos et al., 1995). Water losses from the substrate and the channels and any losses resulting from technical failures were considered negligible. The crop transpiration rate values (equal to crop water consumption) observed, as calculated using Eq. [7], were similar (no statistical difference) for both irrigation frequency treatments (Fig. 6). Crop water consumption ranged between $0.35 \mathrm{~kg} /$ plant $/ \mathrm{d}$ and $0.70 \mathrm{~kg} / \mathrm{plant} / \mathrm{d}$ and the average number of irrigation events per day was 10 and 20 for LIF and HIF treatments, respectively. The mean value of the water applied to the crop during the period of measurements (May to July) was $2.40 \mathrm{~kg} \cdot \mathrm{m}^{-2} \cdot \mathrm{d}^{-1}$ $(0.96 \mathrm{~kg} / \mathrm{pot} / \mathrm{d})$, whereas the corresponding water needs (crop transpiration) were $\approx 1.53$ $\mathrm{kg} \cdot \mathrm{m}^{-2} \cdot \mathrm{d}^{-1}(0.61 \mathrm{~kg} / \mathrm{pot} / \mathrm{d})$. Similar values for gerbera crop transpiration rate during Mediterranean summer conditions have been also found by other authors (Maloupa et al., 1996).

Water use efficiency. Water use efficiency (WUE) is typically defined as the crop yield divided by the amount of water needed for irrigation (Burt et al., 1997). Yield may be given in terms of weight (fresh or dry) or in terms of flower number (Bastug et al., 2006). The corresponding values observed under the two tested irrigation frequencies were 5.87 and $7.64 \mathrm{~g}$ of fresh weight produced per liter of water used for HIF and LIF, respectively. In terms of flower production, the corresponding values found were 0.23 and 0.29 flowers per liter of water used for HIF and LIF, respectively. It was found that to produce one gerbera cut flower, $4.32 \mathrm{~L}$ and 3.47 $\mathrm{L}$ of water were needed under HIF and LIF treatments, respectively.

Crop water status and irrigation scheduling indices. A first attempt to evaluate a RI with a format similar to that of PRI, PRI as an index for crop water status and irrigation scheduling was made in the study. In Figure $7 \mathrm{~A}-\mathrm{B}$, the variation of leaf stomatal resistance and of RI during the period of measurements along with the indication of time that irrigation was performed for LIF and HIF treatments, respectively, is presented. Despite the lack of a clear correlation between RI values and irrigation events, RI seems to be connected with irrigation events because the different irrigation treatments led to different RI fluctuation rates. RI seems to increase after irrigation events with a hysteresis, indicating improved crop water status after irrigation. Similar variations are presented in the values of leaf stomatal resistance $\left(r_{c}\right)$ observed with $r_{c}$ values decreasing after irrigation events. These variations seem to be better correlated to irrigation events for the LIF treatment. Time series analysis (using SPSS 17) was implemented to access the correlation between RI and stomatal resistance. 


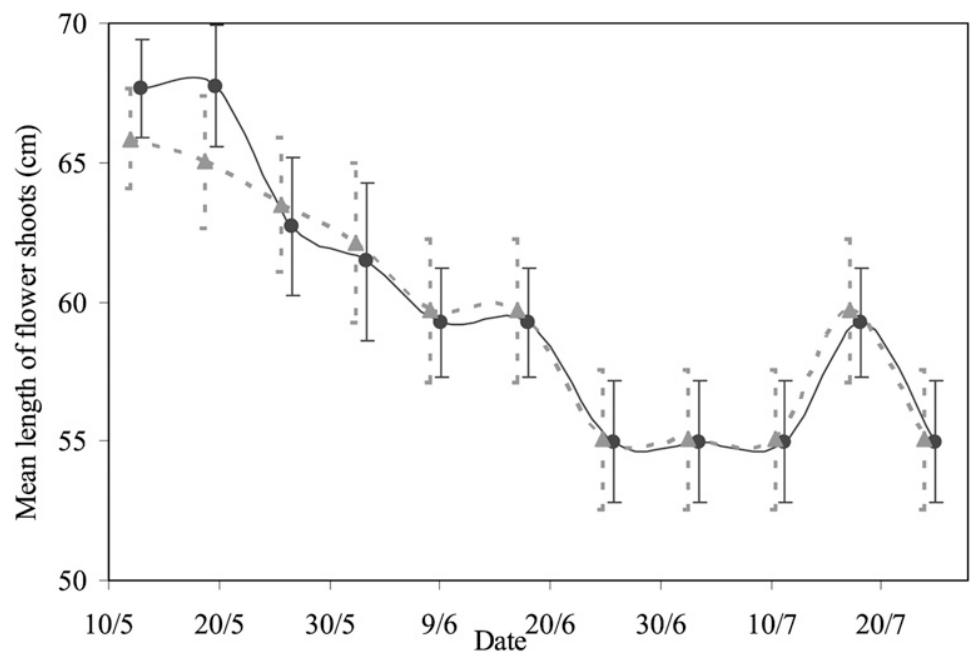

Fig. 4. Evolution of harvested stems' mean length during the period of measurements; circles: low irrigation frequency; triangles: high irrigation frequency (vertical bars depict \pm SES of means of six measurements).

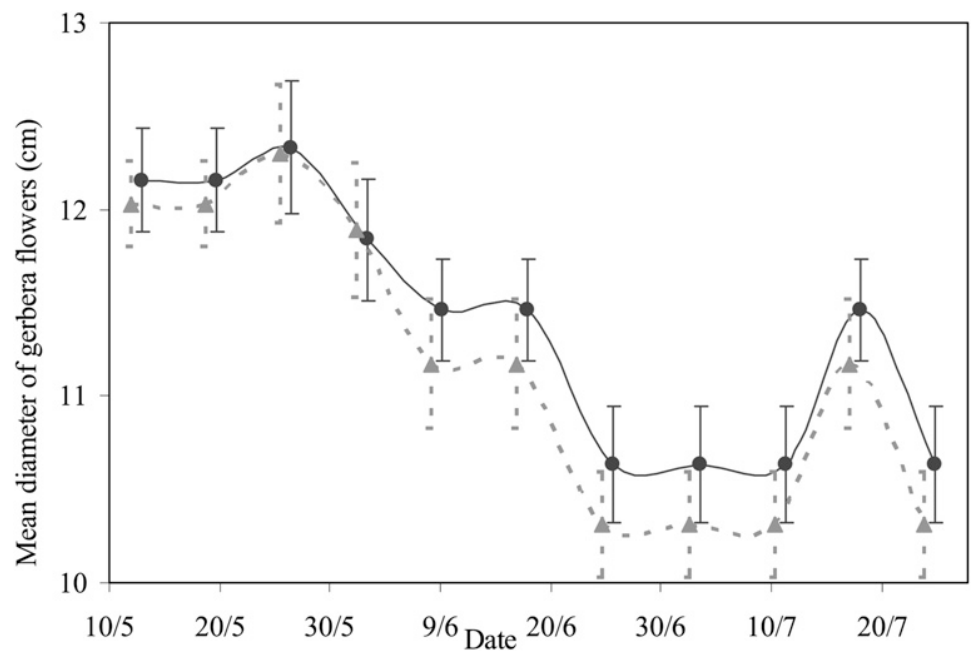

Fig. 5. Evolution of harvested flowers' mean diameter during the period of measurements; circles: low irrigation frequency; triangles: high irrigation frequency (vertical bars depict \pm SES of means of six measurements).

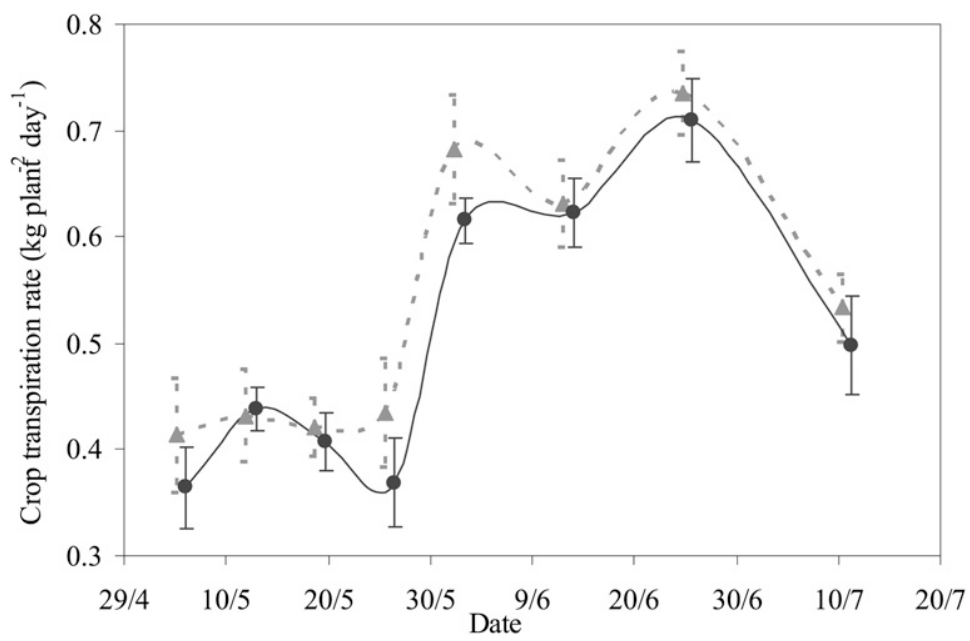

Fig. 6. Evolution of crop transpiration rate during the period of measurements; circles: low irrigation frequency; triangles: high irrigation frequency (vertical bars depict \pm SES of means of six measurements).
Stomatal resistance values for HIF and LIF were modeled using the AR(1) model. Residuals were then used to study crosscorrelations with RI values measured under HIF and LIF, respectively. RI and $r_{c}$ values measured under HIF were not correlated, whereas they were found to be correlated with a lag $=-3$ under LIF. The mean values of stomatal resistance found were 288 (with a SE of $\pm 6.8) \mathrm{s} \cdot \mathrm{m}^{-1}$ and 461 (with a SE of \pm 21 ) $\mathrm{s} \cdot \mathrm{m}^{-1}$ for HIF and LIF, respectively, indicating a difference in plant water status between the two treatments. This difference may also explain the difference of the average values of RI observed for the two treatments, but further investigation is needed to clearly support the findings. Nevertheless, to the authors' best knowledge, no relative information exists on reflectance indexed measurements and use under greenhouse conditions and this may be a first step in this research.

\section{Concluding Remarks}

In the present work, two different irrigation frequencies were tested to evaluate the effect of irrigation frequency on gerbera crop fresh weight, leaf area, and flower yield and quality. The same total amount of water was applied per day to the crops following two schedules, HIF and LIF; and irrigation events were triggered when accumulative solar radiation outside the greenhouse reached $1650 \mathrm{~kJ} \cdot \mathrm{m}^{-2}$ and $3300 \mathrm{~kJ} \cdot \mathrm{m}^{-2}$, respectively.

The applied irrigation frequencies did not affect gerbera yield and quality characteristics (stem length and flower diameter), which followed the same trend and were almost equal for the two treatments. Taking into account these results, it could be concluded that the irrigation frequencies applied were both appropriate because it applied the correct amount of water at acceptable time intervals, which did not significantly affect the physiological status of the crop. Nevertheless, WUE was higher under the LIF treatment than under HIF, which means that for the same amount of water and nutrients consumed, more production was observed under LIF. However, the results observed in this study could not be simply generalized for other crops cultivated to different substrates with different physiological response to irrigation and substrate water status.

Irrigation scheduling has to be applied by a reliable control system that could efficiently online calculate the actual water status of the crop. The development of direct, noncontact, nondestructive and wider sample area methods for data collection for irrigation control purposes is of great interest. In this framework, the reflectance index tested under this work seems to be a promising area for research. Probable issues regarding its use for greenhouse irrigation control use may be related to noise removal (such as interferences by greenhouse framework and machinery shadows, reflectance from crop background, and so on) and definition of threshold values for irrigation scheduling. 

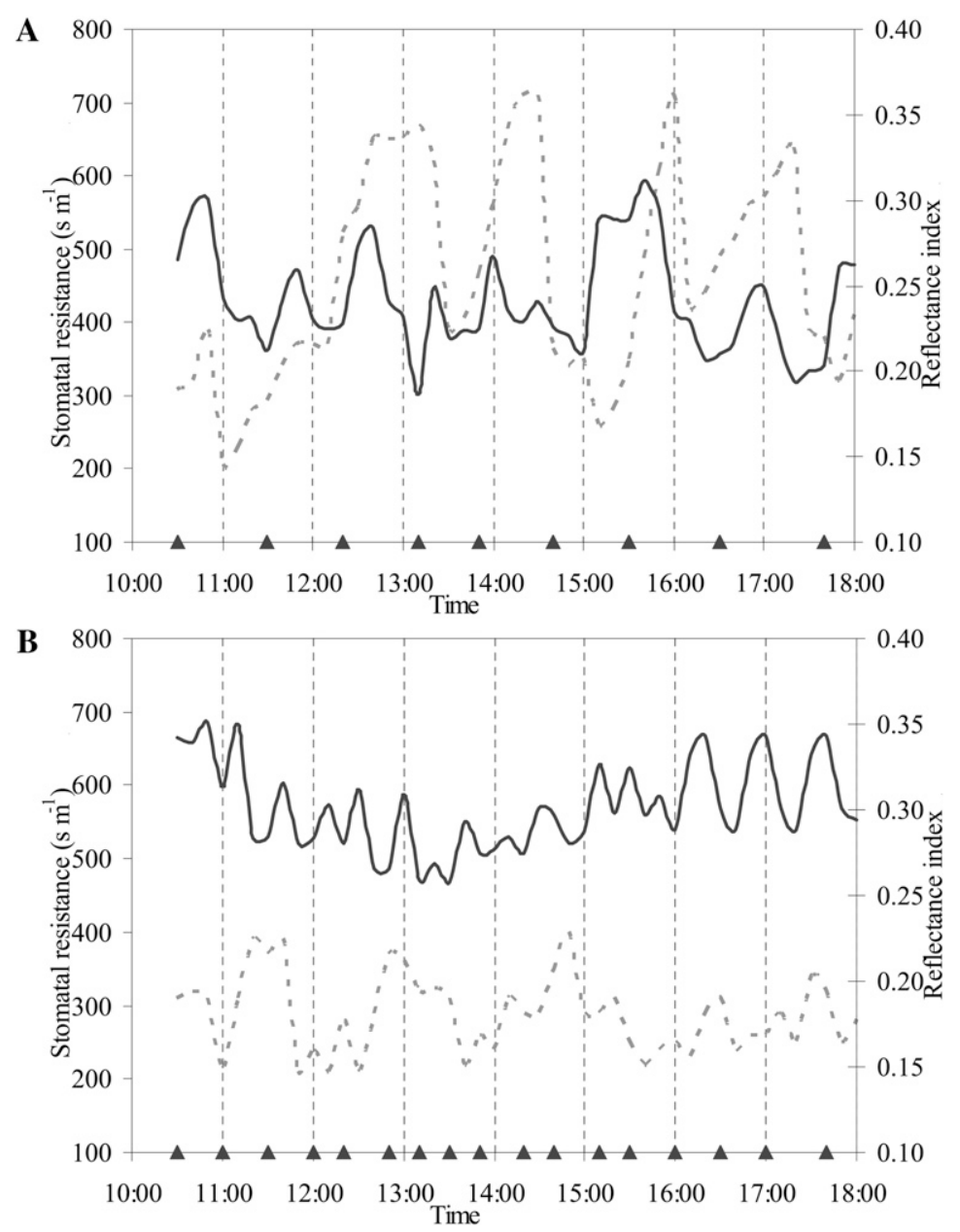

Fig. 7. (A) Evolution of the reflectance index (continue line) and leaf stomatal resistance (discontinue line) during 16 June for high irrigation frequency treatment. Triangles indicate irrigation events. (B) Evolution of the reflectance index (continue line) and leaf stomatal resistance (discontinue line) during 16 June for high irrigation frequency treatment. Triangles indicate irrigation events.

\section{Literature Cited}

Akat, O., I.H. Tüzel, and M.E. Özzambak. 2009. The effects of different salinity levels and leaching fractions on yield and water consumption of gerbera plants. Acta Hort. 807:233-238.

Allen, R.G., L.S. Pereira, D. Raes, and M. Smith. 1998. Crop evapotranspiration: Guidelines for computing crop water requirements. FAO, Rome, Italy.

Anonymous. 2007. Gerbera distinctive breeding catalogue. Florist De Kwakel B.V., De Kwakel, The Netherlands.

Baille, A. 1999. Energy cycle, p. 265-286. In: Stanhill, G. and H. Zvi Encoch (eds.). Ecosystems of the World 20: Greenhouse ecosystems, Elsevier Science Publishers.

Bastug, R., O. Karaguzel, K. Aydinsakir, and D. Buyuktas. 2006. The effects of drip irrigation on flowering and flower quality of glasshouse gladiolus plant. Agr. Water Manage. 81:132-144.

Burt, C., A.J. Clemmens, T.S. Strelkoff, K.H. Solomon, R.D. Bliesner, L.A. Hardy, T.A. Howell, and D.E. Eisenhauer. 1997. Irrigation performance measures: Efficiency and uniformity. J. Irrig. Drain. Eng. 123:423-442.

Ceccato, P., S. Flasse, S. Tarantolac, S. Jacquemoud, and J.M. Gregoirea. 2001. Detecting vegetation
Knipling, E.B. 1970. Physical and physiological basis for the reflectance of visible and nearinfrared radiation from vegetation. Remote Sens. Environ. 1:155-159.

Maloupa, E., M.N. Fakhri, K. Chartzoulakis, and D. Gerasopoulos. 1996. Effects of substrate and irrigation frequency on growth, gas exchange and yield of gerbera cv. Fame. Adv. Hort. Sci. 10:195-198.

Maloupa, E., A. Papadopoulos, and S. Bladenopoulou. 1993. Evapotranspiration and preliminary crop coefficient of gerbera soilless culture grown in plastic greenhouse. Acta Hort. 335:519526.

Manios, V.I., M.D. Papadimitriou, and M.D. Kefakis. 1995. Hydroponic culture of tomato and gerbera at different substrates. Acta Hort. 408: $11-16$.

Moran, M.S., T.R. Clarke, Y. Inoue, and A. Vidal. 1994. Estimating crop water deficit using the relation between surface-air temperature and spectral vegetation index. Remote Sens. Environ. 49:246-263.

Moran, M.S., P. Pinter, B.E. Clothier, and S.G. Allen. 1989. Effect of water stress on the canopy architecture and spectral indices of irrigated alfalfa. Remote Sens. Environ. 29:251-261.

Nantt, D. 2008. CropScan. 20 Dec. 2008. <http:// www.cropscan.com/>.

Papadopoulos, A., E. Maloupa, and F. Papadopoulos. 1995. Seasonal crop coefficient of gerbera soilless culture. Acta Hort. 408:81-90,

Peñuelas, J., J.A. Gamon, A.L. Fredeen, J. Merino, and C.B. Field. 1994. Reflectance indices associated with physiological changes in nitrogen- and water-limited sunflower leaves. Remote Sens. Environ. 48:135-146.

Peñuelas, J., R. Sav, O. Marf, and L. Serrano. 1992. Remotely measured canopy temperature of greenhouse strawberries as indicator of water status and yield under mild and very mild water stress conditions. Agr. For. Meteorol. 58:63-77.

Raviv, M. and J. Blom. 2001. The effect of water availability and quality on photosynthesis and productivity of soilless-grown cut roses. Sci. Hort. 88:257-276.

Riggs, G.A. and S.W. Running. 1991. Detection of canopy water stress in conifers using the airborne imaging spectrometer (AIS). Remote Sens. Environ. 35:51-68.

Robert, C.P. and G. Casella. 2005. Monte carlo statistical methods. 2nd Ed, Springer-Verlag, New York, NY.

Rogers, M.N. and B.O. Tjia. 1990. Gerbera production. Timber Press, Inc., Portland, OR. p. 172-176.

Roh, M.Y. and Y.B. Lee. 1996. Control of amount and frequency of irrigation according to integrated solar radiation in cucumber substrate culture. Acta Hort. 440:332-337.

Schroder, F.G. and H.J. Lieth. 2002. Irrigation control in hydroponics, p. 263-298. In: Savvas, D. and H.C. Passam (eds.). Hydroponic production of vegetables and ornamentals. Embryo Publications, Athens, Greece.

Sonneveld, C. 1989. Rockwool as a substrate in protected cultivation. Chronica Hort. 29:33-36.

Stanhill, G. and A.J. Scholte. 1974. Solar radiation and water loss from glasshouse roses. J. Amer. Soc. Hort. Sci. 99:107-110.

Thenot, F., M. Methy, and T. Winkel. 2002. The photochemical reflectance index (PRI) as a water-stress index. Int. J. Remote Sens. 23: $5135-5139$ 